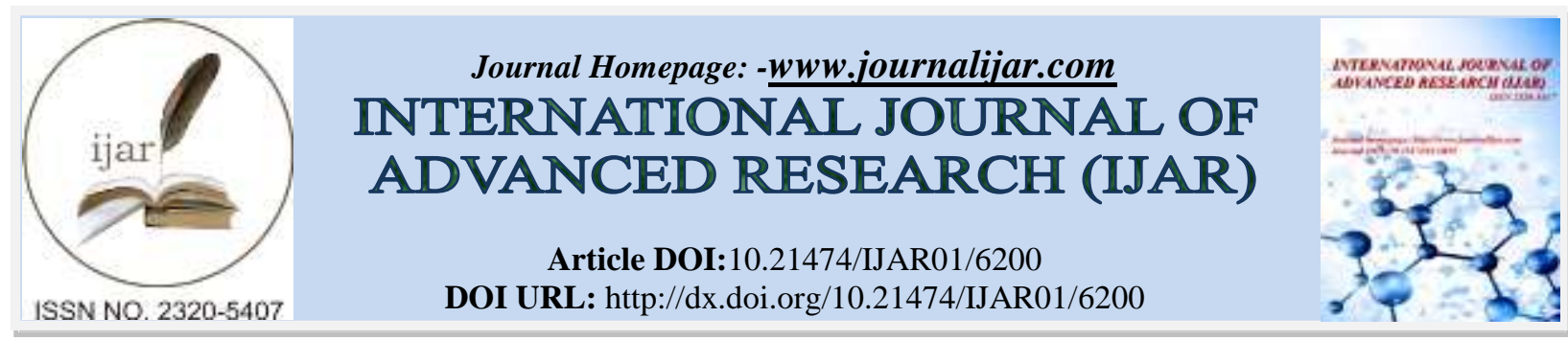

RESEARCH ARTICLE

\title{
INVESTIGATION ON THE MYCODIVERSITY OF FRESH FRUITS OF PHYLLANTHUS EMBLICA L., AN IMPORTANT MEDICINAL PLANT, FROM JAMMU PROVINCE (INDIA).
}

Rohini Sharma and Vishal Sharma.

University of Jammu, Department of Botany, B.R. Ambedkar Road, Jammu-180006.

\section{Manuscript Info}

Manuscript History

Received: 03 November 2017

Final Accepted: 05 December 2017

Published: January 2018

Key words:-

Medicinal Plant, Mycoflora,

mycopathogens, Phyllanthus emblica

\begin{abstract}
An investigation of mycoflora was carried out from market samples of fresh fruit of Phyllanthus emblica L., an important medicinal plant of India. The samples were collected from various wholesale and retail shops as well as orchards of Jammu province. A total of 25 fungal species representing 12 genera were recovered by using surface washing technique. Presence of low $\mathrm{pH}$ and sugars and high content of moisture and vitamin $\mathrm{C}$ and other nutrients in the fresh fruit of $P$. emblica were the prominent factors which made it prone to such a large number of mycopathogens. Assessment of mycobial load of P. emblica showed the presence of many such fungal species that are widely acknowledged as the most important mycotoxin producers. Lack of proper knowledge and use of unscientific methods of collection and storage of these fresh fruits of amla leads to their contamination. In view of the detected mycobial contamination, an urgent need for proper collection and storage of amla fruit is ardently required.
\end{abstract}

Copy Right, IJAR, 2018,. All rights reserved.

\section{Introduction:-}

India is endowed with a rich wealth of medicinal plants and a strong base of many systems of medicines including Ayurveda, Unani, Sidha and other local health practices. The curative properties of medicinal plants are due to the presence of complex chemical substances including alkaloids, glycosides, corticosteriods and essential oils (Silva $e t$ $a l, .2011)$. It has been observed that despite spectacular advancement in modern synthetic drugs, the viability and popularity of indigenous systems of medicine and use of medicinal plants in curing various minor and major health ailments is still intact in our country. However, despite the rich heritage of medicinal plants, India has not been able to capitalize on its medicinal wealth, chiefly because the quality of crude botanicals and finished medicinal plant products is adversely affected by a number of internal and external factors right from harvesting to processing (Dubey et al., 2004). Another effect is that these medicinal plants also undergo deterioration even before they are used in making drugs. Realizing the fact that mycopathogenic contamination of medicinal plants has not received the attention that the magnitude of the problem warrants and since no such work has been attempted from Jammu and Kashmir State, which is a large reservoir of medicinal plants, an investigation was undertaken on one such important medicinal plant, Phyllanthus emblica L.

Phyllanthus emblica, which is known by the common name amla, belongs to family Euphorbiaceae (Hooker, 1897). It is reported to be native of India and is therefore, commonly called as Indian gooseberry. Commercial cultivation of amla is done in Uttar Pradesh (Bajpai, 1963) but in other Indian states its cultivation is increasing rapidly because of its high medicinal value and great commercial potential. Some of the cultivated varieties of amla, well-known in 
our country for their large fruits are Banarasi, Chakaiya and Hathijhool. Fruit of amla is very rich source of vitamin C (400-600mg/100g) and also contain calcium, phosphorous, iron, nicotinic acid and various amino acids like asparatic acid, alanine, glutamic acid, lysine and proline (Hanif, 1966). An inventiorization of medicinal plants shows that amla fruits are cardioprotective, antiscorbutic, diuretic and laxative (Bajpai et al., 1985). In view of its medicinal importance, many pharmaceutical industries are engaged in using amla fruit for the preparation of famous 'Triphala', 'Chawanprash' and many other ayurvedic formulations like Brahmarasayan, Sanjivani-vati, Agnitundivati and Arogyavardhini etc.

According to Sharma and Koul, (1999), almost every horticultural produce is high in moisture and nutrients and thus susceptible to injury and subsequent attack by variety of mycopathogens. Like others fruits, Phyllanthus emblica is also susceptible to mycobial infections at the pre- and post-harvest stage. These fruits have very low $\mathrm{pH}$ and therefore, may be attacked by a unique group of fungi, which have specific nutritional requirement and enzymatic capabilities that permit them to develop fruit rot. Thus, an investigation was undertaken to isolate, purify and identify the mycopathogens associated with the market samples of fresh fruit of this plant and their possible role in causing fruit rot.

\section{Materials and Methods:-}

\section{(i) Isolation of mycoflora and their identification}

Fresh fruit samples of selected medicinal plant was collected in pre-sterilized polythene bags from various wholesale and retail shops as well as various orchards of Jammu province. Sample bags were brought to the laboratory, sealed over flame to avoid external contamination and kept in the refrigerator at $5-7^{\circ} \mathrm{C}$ to prevent undesirable changes till further studies were conducted. Surface mycoflora associated with market samples of Phyllanthus emblica was determined by using surface washing technique (Singh and Kainsa, 1983). Isolation of mycopathogens from the samples were made on Czapek Dox agar (CDA) medium. The petriplates were incubated for 7 days at $28 \pm 2^{\circ} \mathrm{C}$ till proper growth of the fungal colonies was obtained. The recovered fungal species were identified by studying their macro and micro-morphological characters. For the purpose of identification, the isolated fungal species were grown and made to sporulate on different culture media, such as potato dextrose agar medium (PDA), malt extract agar medium (MEA), Czapek yeast agar medium (CYA), potato carrot agar medium (PCA) and water agar medium (WA). Identification of fungal species was done by using various keys and other relevant literature given by Brown and Smith (1957), Rapper and Fennel (1965), Tandon (1968), Rifai (1969), Booth (1971), Ellis (1971, 1976), Barron (1972), Pitt (1979), Domsch et al. (1980), Onions et al. (1981) Schipper (1984), Pitt and Hocking (1985), Gams (1997) and Chowdhary et al. (2000).

(ii) Percentage colonization frequency $(\mathrm{CF} \%)$ and $\mathrm{A} / \mathrm{F}$ ratios of the recovered fungal species

Percentage colonization frequency $(\mathrm{CF} \%)$ and $\mathrm{A} / \mathrm{F}$ ratios were calculated for each fungal species from various samples by using the following formulae:

$$
\mathrm{CF}(\%)=\frac{\text { Number of samples colonized by a specific fungi }}{\text { Total number of samples studied }} \times 100
$$

On the basis of percentage colonization frequency, each of the recovered fungal species is distributed among five frequency classes (Raunkiaer,1934) :

$\begin{array}{cc}\text { Frequency class } & \text { Frequency } \% \\ \text { A } & 0-20 \\ \text { B } & 21-40 \\ \text { C } & 41-60 \\ \text { D } & 61-80 \\ \text { E } & 81-100\end{array}$

$\mathrm{A} / \mathrm{F}$ ratio $=\quad$ Abundance

Colonization frequency

where, abundance $=\frac{\text { Total number of colonies of a specific fungi }}{\text { Number of samples colonized by a specific fungi }}$ 
$\mathrm{A} / \mathrm{F}$ ratios describe the distribution pattern of each fungal species into one of the following three categories: $\mathrm{A} / \mathrm{F}$ ratio of $<0.025$ depicts that the fungal species has regular distribution.

$\mathrm{A} / \mathrm{F}$ ratio between $0.025-0.05$ depicts that fungal species has random distribution.

$\mathrm{A} / \mathrm{F}$ ratio of $>0.05$ depicts that the fungal species has contageous distribution.

\section{Results:-}

During the period under investigation, 25 fresh samples of fruit of Phyllanthus emblica collected from various wholesale and retail shops as well as various orchards of Jammu province were studied for fungal flora. In all, 25 fungal species belonging to 12 genera were recovered (Table 1). The fungal species recovered from the various fresh fruit samples of Phyllanthus emblica included members of Zygomycetes, Ascomycetes and Deuteromycetes. Class Zygomycetes was represented by two species of Mucor (M. hiemalis and M. microsporus) and one species of Rhizopus ( $R$. stolonifer). Ascomycetes was represented by Emericella nidulans var. echinulatus, whereas Deuteromycetes consisted of maximum representation including nine species of Aspergillus ( A. japonicus, A. flavus, A. fumigatus, A. niger, A. nidulans, A. parasiticus, A. ochraceous, A. terreus and A. sydowii); three species of Penicillium ( $P$. chrysogenum, $P$. funiculosam and $P$. waksmanii); two species each of Fusarium $(F$. verticilloides and $F$. solani); Cladosporium (C. cladosporioides and C. oxysporum) and Paecilomyces (P. liliacinus) and one species each of Acremonium (Acremonium implicatum); Alternaria (Alternaria alternata); Doratomyces (Doratomyces purpureofuscus); Curvularia (Curvularia lunata) and Trichothecium (Trichothecium roseum).

Their values for abundance, colonization frequency percentage (CF\%) and abundance/frequency ratio (A/F ratio) are depicted in table 1. Perusal of data shows Penicillium funiculosum with maximum colonization frequency (50), closely followed by Aspergillus terreus, Cladosporium oxysporum and Fusarium verticilloides with $45 \% \mathrm{CF}$ and thus belonging to the Raunkiaer's frequency class C. Aspergillus ochraceous and Emericella nidulans var. echinulatus represented the rare fungal species and belonged to Raunkiaer's frequency class A, since both these species were present in less than $10 \%$ of the total samples. Percentage colonization frequency (CF\%) of micromycetes of $P$. emblica was also represented in figure 1 .

\section{Discussion:-}

This study clearly indicates that various aspergilli and penicilli including Aspergillus japonicus, A. flavus, A. fumigatus, A. niger, A. nidulans, A. parasiticus, A. ochraceous, A. terreus, Penicillium chrysogenum, $P$. funiculosum and P. waksmanii are commonly associated with the samples of fruit of Phyllanthus emblica. In addition, some other mycofungi including Emericella, Paecilomyces and Curvularia etc. were also recovered from investigated medicinal plants. Realizing the importance of the quality of medicinal plants, a large number of workers have recently engaged themselves in the study of surface mycoflora of various herbal drug plants during storage and marketing (Aziz et al., 1998; Stevic et al., 2012). These workers reported diverse range of fungal species belonging mainly to Aspergillus, Penicillium, Rhizopus, Chaetomium, Fusarium, Eurotium and Cladosporium.

In the present investigation, fresh fruits of amla were contaminated with a plethora of fungal species. These fungal genera might had reached the fruit surface directly from the orchard or during picking and packing operations or they might had been carried along with the packing leaves, straw and baskets or might had originated within the enclosure of fruit and vegetable shops (Meredith, 1961; Panduranjan and Suryanarayanan, 1985; Sumbali and Badyal, 1990). Another possible reason for the fruit contamination is that it continues to respire after harvesting, the resultant heat accelerates respiration and ageing which in turn makes the fruit even more susceptible to the attack by Mycoflora (Dasgupta and Mandal,1989). This showed that fruit surface is an important habitat, which influences the occurrence and development of rot. Some of the fungal spores present on the fruit surface may colonise the host on getting a suitable microhabitat while some get killed due to unfavorable conditions or due to antagonistic effect of other microorganisms present on the surface. Similar observations have also been made by Kalafatoglue and Karapinar (1989) while working on the surface mycoflora of other fruits.

\section{Conclusion:-}

In the present investigation, detection of large number of mycopathogens from the fresh fruit samples of Phyllanthus emblica clearly indicates that its powdered formulations are not completely safe for direct human consumption. However, due to lack of proper knowledge and use of unscientific methods of collection and storage these fresh fruits of amla may become prone to contamination with fungal spores. In view of the detected mycobial contamination, an urgent need for proper collection and storage of the fruit of amla is ardently required. 
Table 1:-Percentage Colonization Frequency, abundance and A/F ratios of the recovered micromycetes from fruit of Phyllanthus emblica

\begin{tabular}{|c|c|c|c|c|c|c|}
\hline $\begin{array}{l}\text { S. } \\
\text { No }\end{array}$ & & $\begin{array}{l}\text { Number } \\
\text { of } \\
\text { samples } \\
\text { colonized }\end{array}$ & $\begin{array}{l}\text { Total } \\
\text { colonies } \\
\text { recovered }\end{array}$ & $\begin{array}{l}\text { CF } \\
(\%)\end{array}$ & Abundance & $\mathrm{A} / \mathrm{F}$ ratio \\
\hline 1 & Alternaria alternata & 8 & 18 & 40 & 2.25 & 0.0563 \\
\hline 2 & Acremonium implicatum & 5 & 12 & 25 & 2.40 & 0.0960 \\
\hline 3 & Aspergillus niger & 6 & 9 & 30 & 1.50 & 0.0500 \\
\hline 4 & Aspergillus japonicus & 5 & 9 & 25 & 1.80 & 0.0720 \\
\hline 5 & Aspergillus terreus & 9 & 18 & 45 & 2.00 & 0.0444 \\
\hline 6 & Aspergillus ochraceous & 1 & 3 & 5 & 3.00 & 0.6000 \\
\hline 7 & Aspergillus flavus & 3 & 5 & 15 & 1.67 & 0.1111 \\
\hline 8 & Aspergillus parasiticus & 6 & 11 & 30 & 1.83 & 0.0611 \\
\hline 9 & Aspergillus fumigatus & 6 & 16 & 30 & 2.67 & 0.0889 \\
\hline 10 & Aspergillus nidulans & 4 & 13 & 20 & 3.25 & 0.1625 \\
\hline 11 & Aspergillus sydowii & 6 & 13 & 30 & 2.17 & 0.0722 \\
\hline 12 & Cladosporium oxysporum & 9 & 24 & 45 & 2.67 & 0.0593 \\
\hline 13 & Cladosporium cladosporioides & 6 & 18 & 30 & 3.00 & 0.1000 \\
\hline 14 & Doratomyces purpureofuscus & 4 & 9 & 20 & 2.25 & 0.1125 \\
\hline 15 & $\begin{array}{lll}\begin{array}{l}\text { Emericella } \\
\text { echinulatus }\end{array} & \text { nidulans var. } \\
\end{array}$ & 1 & 4 & 5 & 4.00 & 0.8000 \\
\hline 16 & Fusarium solani & 3 & 9 & 15 & 3.00 & 0.2000 \\
\hline 17 & Fusarium verticilloides & 9 & 16 & 45 & 1.78 & 0.0395 \\
\hline 18 & Mucor hiemalis & 4 & 12 & 20 & 3.00 & 0.1500 \\
\hline 19 & Mucor microsporus & 3 & 6 & 15 & 2.00 & 0.1333 \\
\hline 20 & Paecilomyces liliacinus & 3 & 6 & 15 & 2.00 & 0.1333 \\
\hline 21 & Penicillium chrysogenum & 7 & 22 & 35 & 3.14 & 0.0898 \\
\hline 22 & Penicillium funiculosum & 10 & 31 & 50 & 3.10 & 0.0620 \\
\hline 23 & Penicillium waksmanii & 3 & 6 & 15 & 2.00 & 0.1333 \\
\hline 24 & Rhizopus stolonifer & 3 & 10 & 15 & 3.33 & 0.2222 \\
\hline 25 & Trichothecium roseum & 7 & 20 & 35 & 2.86 & 0.0816 \\
\hline
\end{tabular}

$\mathrm{CF}(\%)$ - Colonization frequency percentage

A/F ratio - Abundance / Frequency ratio 


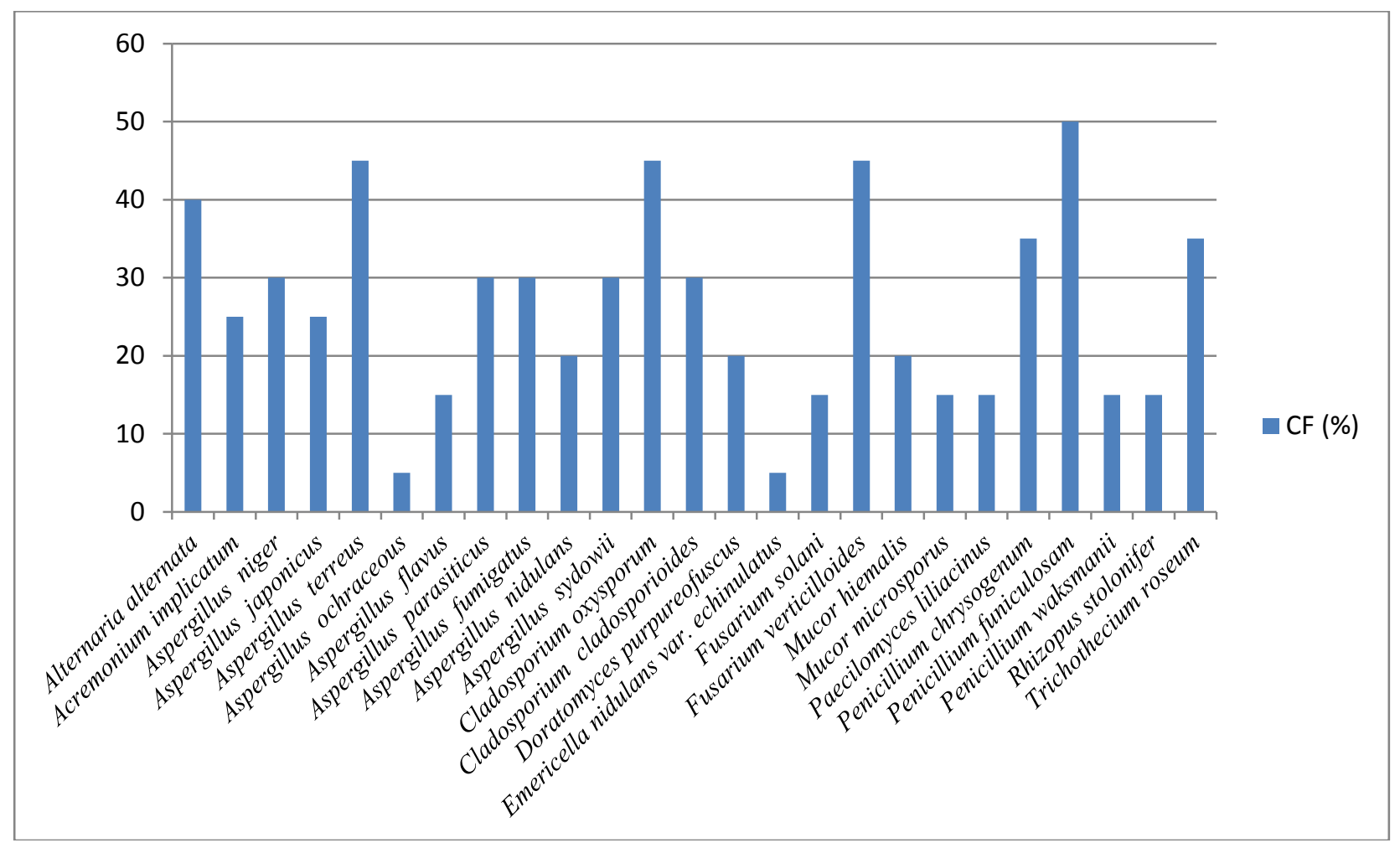

Fig. 1:- Percentage colonization frequency (CF\%) of recovered mycoflora from P. emblica
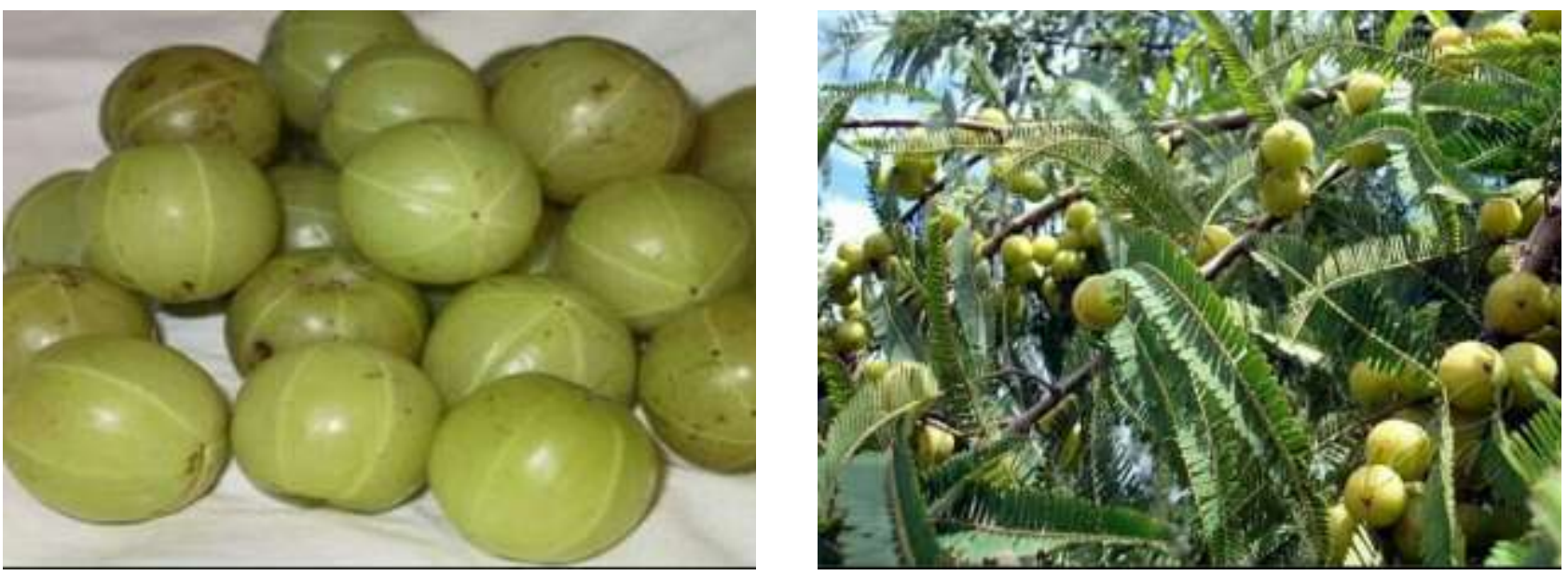

Fig. 1:-Sample of fresh fruit of amla from markets and orchard of Jammu region

\section{Acknowledgement:-}

The authors are thankful to Head, Department of Botany, University of Jammu for providing laboratory facilities.

\section{References:-}

1. Aziz, N. H., Youssef, Y. A., El-Fouly, M. Z. and Moussa, L. A. (1998). Contamination of some common medicinal plant samples and spices by fungi and their mycotoxins. Botanical Bulletin of Academic Sinica. 39 (4): 279-285.

2. Bajpai, P.N. (1963). Ph.D. Thesis, Agra University, Agra.

3. Bajpai,P.N., Shukla,H.S. and Chaturvedi, O.P. (1985). History importance and scope of tropical and subtropical fruits in India. In : Fruits of India (Ed. Bose, T.K.). NayaPrakash : Calcutta six: India, pp. 1-20. 
4. Barron, G.L. (1972). The genera of Hyphomycetes from soil. Robert E. Krieger Publishing Company, Huntington, New York. pp. 1-364.

5. Booth, C. (1971). The genus Fusarium. Commonwealth Mycological Institute Kew, Surrey, England. pp. 1-237.

6. Brown, A.H.S. and Smith, G. (1957). The genus PaecilomycesBainer and its perfect stage Byssochlamys Westling. Transactions of the British Mycological Society 40: 17-89.

7. Chowdhary,P.N., Lal, S.P., Mathur, N. and Singh, D.V. (2000). Manual on identification of plant

8. Dasgupta,M.K. and Mandal, N.K. (1989)Post harvest pathology of perishables. Oxford and IBH Publishing Co. Pvt. Ltd. New Delhi, pp.623.

9. Domsch, K.H. and Gams, W. and Anderson, T.H. (1980). Compendium of soil fungi. Academic Press, London. pp. 1-859.

10. Dubey, N. K., Kumar, R. and Tripathi, P. (2004). Global promotion of herbal medicine : India's opportunity. Current Science. 86(1): 37-41.

11. Ellis, M.B. (1976). More DematiaceousHyphomycetes. Commonwealth Mycological Institute Kew, Surrey, England. pp. 1-507.Elmes GW (1991). Ant colonies and environmental disturbances. Symposium of the Zoological Society of London 63: 15-32.Gams W (1997). Cephalosporium like Hyphomycetes. Hyphomycetes course, Sugadaira, Japan. pp. 1-122.

12. Hanif, M. (1966). Pakistan J. Sci. Res, 18:61-63

13. Hooker, J.D. (1897). Flora of British India; The University of California: 1-149.

14. Institute, New Delhi. pp. 1-148.

15. Kalafatoglue, H. and Karapinar, M (1989). Investigation of spoilage Mycoflora in selected apple cultivars during storage. UniversiteriZirrat. Dergisi. 26: 347-356.

16. Meredith, D.S. (1961). Botryodiplodia theobromae and Nigrospora species in the air of a Jamaican banana plantation. Nature, 196: 555-557.

17. Onions, A.H.S., Allsopp, D. and Eggins, H.O.W. (1981). Smith's Introduction to Industrial Mycology. Edward Arnold, London. pp. 1-398.

18. Pandurangan,A.G. and Suryanarayan, T.S. (1985). A survey of Mycoflora associated with some fresh vegetables and fruits in a market at Saidapet. Madras. J. Econ. Taxon. Bot. 7: 309-315.

19. pathogenic and biocontrol fungi of agricultural importance. Indian Agricultural Research

20. Pitt, J.I. (1979). The genus Penicillium and its teleomorphic states Eupenicillium and Talaromyces. Academic Press, London. pp. 1-634.

21. Pitt, J.I. and Hocking, A.D. (1985). Fungi and Food Spoilage. CSIRO Division of Food Research, Academic Press, Sidney. pp 1-413.

22. Rapper, E.B. and Fennel, D.I. (1965). The genus Aspergillus. The Williams and Wilkins Company, Baltimore, USA. pp. 132-575.

23. Rifai, M.A. (1969). A review of the genus Trichoderma. Herbarium Bogoriense, Bogor, Java, Indonesia. pp. 155.Schipper MAA (1984). A revision of the genus Rhizopus. Studies in Mycology 25: 1-33.Stone RH and Ndu FOC (1985). New Biology for West African Schools, New York, Longmans Group Limited.

24. Roy, A. K. and Chourasia, H. K. (2001). Mycotoxin contamination in herbal seed samples under storage and their prevention. In : Seed technology and seed pathology. (Eds. Singh, T and Agrawal, K.), Pointer Publishers, Jaipur, India.

25. Sharma, R.C. and Koul, J.L. (1999). Post-harvest disease of temperate fruits and their management. In. Diseases of horticultural crops : Fruits (Eds. Verma, L.R and Sharma, R.C) Indus Publishing Company, New Delhi, pp. 582-623.

26. Silva, J.O.C., Costa, R.M.R., Teixeira, F.M. and Barbosa W.L.R. (2011). Processing and Quality Control of Herbal Drugs and Their Derivatives. Prof. Yukihiro Shoyama (Ed.), ISBN: 978-953-307-682-9.

27. Singh, J.P. and Kainsa, R.L. (1983). Microbial flora of grapes in relation to storage and spoilage. Indian Phytopathol. 36:365-366.

28. Stevic, T., Pavlovic, S., Stankovic, S., and Savikin, K. (2012). Pathogenic microorganisms of medicinal herbal drugs. Arch. Biol. Sci., Belgrade, 64 (1), 49-58.

29. Sumbali, G and Badyal, K. (1990). New records of fungal species associated with the fruit rot of Phyllanthus emblica Linn. Indian J. Mycol. And Plant Pathol. 20:202-203.

30. Tandon, R.N. (1968). Mucorales of India. Indian Council of Agricultural Research, New Delhi. pp. 1-120. 